\title{
Hubungan Kualitas Pelayanan Rawat Inap Dengan Indeks Kepuasan Masyarakat Puskesmas Wonosari
}

\section{Lilik Mulyati', Sri Astutik Andayani2, Joko Prananto $^{3}$}

1. Puskesmas Wonosari Bondowoso, Email: lilikmulyati80@gmail.com

2. Universitas Nurul Jadid Paiton Probolinggo

3. RSUD. Dr. Koesnadi Bondowoso

\section{ABSTRACT}

Community satisfaction measurements are intended to determine the level of community satisfaction with the services provided and provide an opportunity for the community to assess the services that have been received.The design of this study is quantitative with a Cross-Sectional approach. The study was conducted by involving 59 respondents taken by accidental sampling. The study was conducted in April until May 2019 at Wonosari Health Center, Bondowoso Regency. The measuring instrument used was a questionnaire, then bivariate analysis was performed with Spearman Rank Analysis, with a significance of $p=0.05$. The results of the Spearman Rank statistical test with significance levels $p<0.05$. Obtained p-value 0,000 which means There is a Relationship between the Quality of Inpatient Services and the Wonosari Community Health Center Community Satisfaction Index with a correlation coefficient of 0.714. The quality of inpatient care results in an index of community satisfaction when receiving health services provided. The quality of this service can ultimately provide several benefits, including the establishment of harmonious relationships between service providers and customers, providing a good basis for creating customer loyalty and building a favorable recommendation for these service providers.

Keywords: Public Health Center, Quality, Inpatient, Index of Community Satisfaction 


\section{ABSTRAK}

Pengukuran kepuasan masyarakat dimaksudkan untuk mengetahui tingkat kepuasan masyarakat terhadap layanan yang diberikan serta memberikan kesempatan kepada masyarakat untuk menilai layanan yang telah diterima. Rancangan penelitian ini bersifat kuantitatif dengan pendekatan CrossSectional. Penelitian dilakukan dengan melibatkan 59 responden yang diambil secara accidental sampling. Penelitian dilakukan pada bulan April sampai dengan Mei 2019 di Puskesmas Wonosari, Kabupaten Bondowoso. Alat ukur yang digunakan adalah kuesioner, selanjutnya dilakukan Analisa bivariat dengan Analisa Spearman Rank, dengan signifikansi $\mathrm{p}=0,05$. Hasil uji statistik Spearman Rank dengan derajat kemaknaan $\mathrm{p}<0,05$. Didapatkan $\mathrm{p}$ value 0,000 yang berarti Ada Hubungan Kualitas Pelayanan Rawat Inap Dengan Indeks Kepuasan Masyarakat Puskesmas Wonosari dengan tingkat Correlation Coefficient 0,714. Kualitas pelayanan rawat inap berakibat pada indeks kepuasan masyarakat saat menerima pelayanan kesehatan yang diberikan. Kualitas layanan ini pada akhirnya dapat memberikan beberapa manfaat, diantaranya terjalinya hubungan yang harmonis antara penyedia layanan dan pelangan, memberikan dasar yang baik terciptanya loyalitas pelanggan dan membangun suatu rekomendasi yang menguntungkan bagi penyedia layanan tersebut

Kata Kunci: Pusat Kesehatan Masyarakat, Kualitas, Rawat Inap, Indek Kepuasan Masyarakat 


\section{Pendahuluan}

Pemerintah menyelenggarakan pelayanan kesehatan mulai dari pelayanan kesehatan primer di tingkat pusat kesehatan masyarakat (Puskesmas), pelayanan kesehatan sekunder di tingkat pelayanan rumah sakit dengan pelayanan spesialis, dan pelayanan kesehatan tertier yaitu rumah sakit dengan pelayanan sub spesalis (Lestari D,DKK. 2015).

Peraturan menteri kesehatan republik Indonesia nomor 75 tahun 2014 tentang Pusat Kesehatan Masyarakat (Puskesmas) merupakan fasilitas pelayanan kesehatan yang menyelenggarakan upaya kesehatan masyarakat dan upaya kesehatan perseorangan tingkat pertama, dengan lebih mengutamakan upaya promotif dan preventif, untuk mencapai derajat kesehatan masyarakat yang setinggitingginya di wilayah kerjanya.

Sebagai ujung tombak pelayanan dan pembangunan kesehatan di Indonesia, maka puskesmas perlu mendapatkan perhatian terutama berkaitan dengan kualitas pelayanan kesehatan puskesmas sehingga dalam hal ini puskesmas dituntut untuk selalu meningkatkan profesionalisasi dari para pegawainya serta meningkatkan fasilitas atau sarana kesehatannya untuk memberikan kepuasan kepada masyarakat pengguna jasa layanan kesehatan.

Berdasarkan profil Dinas Kesehatan propinsi Jawa Timur pada tahun 2016 terdapat 444.665 orang yang memanfaatkan layanan kesehatan rawat inap dan pada tahun 2017 terdapat 395.389 orang (Profil Kesehatan Propinsi Jawa Timur). Dan dari telaah peneliti sekaligus perawat di Puskesmas Wonosari selama 3 tahun terakhir terdapat penurunan secara signifikan pemanfaatan layanan kesehatan khususnya pada pasien rawat inap dimana data menunjukkan terjadinya penurunan dari semua komponen rawat inap. Tahun 2016 jumlah pasien 1.471 dengan jumlah hari perawatan 2.114 hari perawatan, Tahun 2017 jumlah pasien sebanyak 1.017 pasien dengan jumlah hari perawatan sebanyak 2.786 hari perawatan, sedangkan pada Tahun 2018 (Rekapitulasi laporan Rawat Inap
Puskesmas Wonosari). Penyebab penurunan jumlah pasien ini tentunya perlu ditelaah lebih jauh karena secara umum menunjukkan semakin menurunnya pemanfaatan layanan rawat inap Puskesmas Wonosari.

Hasil penelitian Rahmah Hida Nurrizka (2011) menunjukkan kepuasan masyarakat terhadap pelayanan kesehatan, keluhan pelayanan yang sering diutarakan oleh masyarakat terhadap pelayanan dirawat inap adalah persoalan kebersihan dan proses menunggu untuk mendapatkan perawatan yang cenderung lama. Hampir sekitar 27\%$30 \%$ dari pasien yang merasakan dua poin tersebut yang sering menjadi persoalan dalam memanfaatkan layanan medis. Selain itu, pelayanan yang relatif jauh dari komunitas masyarakat menyulitkan masyarakat mendapatkan pelayanan yang optimal. Beberapa proses pelayanan terhadap masyarakat juga kurang memberikan kepuasan, tidak ada kejelasan dari petugas medis kepada pasien tentang penyakit yang diderita, pasien yang terbatas untuk memberikan komentar sehingga kecenderungan tugas mendominasi satu arah terhadap pelayanan juga menjadi kendala yang menyebabkan pasien menjadi tidak puas terhadap pelayanan yang diberikan. Ini memberikan sebuah petunjuk bahwa masih banyak hal-hal pelayanan yang perlu ditingkatkan untuk setiap jenis unit kesehatan di Indonesia. Sejalan dengan hal tersebut, penelitian terbaru yang dilakukan oleh mulyadi (2018) terhadap 100 sampel menunjukkan hubungan yang signifikan mutu pelayanan kesehatan dengan kepuasan pasien di puskesmas.

Pengukuran

kepuasan masyarakat dimaksudkan untuk mengetahui tingkat kepuasan masyarakat terhadap layanan yang diberikan serta memberikan kesempatan kepada masyarakat untuk menilai layanan yang telah diterima. Hal ini sebagai upaya untuk meningkatkan kualitas pelayanan serta mempercepat upaya pencapaian sasaran 
terhadap kinerja aparatur negara dalam

penyelenggaraanpelayanan

rangka

publik.

Menurut Puguh Hariyanto, Standart pelayanan dan kepuasan masyarakat sering dilupakan, Hasil evaluasi menunjukkan sejauh ini pelayanan masih belum optimal. Hal itu dapat dilihat dari masih banyaknya keluhan yang disampaikan masyarakat di media massa dan jejaring sosial. Jika keluhan-keluhan ini tidak ditanggapi, akan timbul rasa tidak percaya oleh masyarakat terhadap pemerintah (Widi Utami, 2016). Oleh karena itu, Puskesmas dituntut untuk selalu menjaga kepercayaan dan Kepuasan pasien/konsumen dengan meningkatkan kualitas pelayanan agar kepuasan pasiennya meningkat. Kualitas layanan ini pada akhirnya dapat memberikan beberapa manfaat, diantaranya terjalinya hubungan yang harmonis antara penyedia layanan dan pelangan, memberikan dasar yang baik terciptanya loyalitas pelanggan dan membangun suatu rekomendasi dari mulut kemulut yang menguntungkan bagi penyedia layanan tersebut. Dalam perspeksi islam kebaikan yang kita berikan akan kembali pada kita, sebagaimana tercantum dalam Al Qur'an surah Al Isra ayat 7.

$$
\text { Berdasarkan profil Dinas }
$$

Kesehatan kabupaten Bondowoso, terdapat 25 Puskesmas yang tersebar di 23 kecamatan, yang secara kompherensif memberikan pelayanan kesehatan tingkat pertama. Salah satu fungsi dari puskesmas adalah menitik beratkan pada upaya preventif dan promotive dengan tidak mengabaikan upaya kuratif dan rehabilitative (Profil Dinas Kesehatan Kabupaten Bondowoso). Pelayanan rawat inap merupakan pelayanan kesehatan perorangan yang meliputi observasi, diagnosa, pengobatan, keperawatan, rehabilitasi medik dengan menginap di ruang rawat inap pada sarana kesehatan rumah sakit pemerintah dan swasta, serta puskesmas perawatan dan rumah bersalin, yang oleh karena penyakitnya penderita harus menginap (Pradana M. Sungging. 2015).

Pihak puskesmas perlu secara cermat menentukan kebutuhan konsumen (dari sudut pandang mereka) sebagai upaya untuk memenuhi keinginan dan meningkatkan kepuasan atas pelayanan yang diberikan. Menjalin hubungandan melakukan penelitian terhadap mereka perlu dilakukan, agar pelayananyang diberikan sesuai dengan yang diharapkan. Hal inilah yang disebut fokus/orientasi pada pelanggan. Fokus pada pelanggan merupakan dasar dari pelaksanaan fungsi pemasaran, selanjutnya dijelaskan bahwa pemasaran selalu berupaya agar perusahaan selalu berhubungan erat dengan para pelanggannya. Gambaran ini dicerminkan dari upaya puskesmas untuk selalu dapat dengan tepat mengidentifikasikan apa yang dibutuhkan dan diinginkan pelanggannya, dan berupaya memperkecil perbedaan (gap) antara apa yang diinginkan dari pelayanan yang diberikan puskesmas dengan apa yang sebenarnya mereka terima. Memperhatikan data pasien/konsumen (Dinik Retnowati. 2016). Puskesmas Wonosari tahun 2016 sampai dengan tahun 2018 terlihat mengalami naik turun. Hal ini mengindikasikan adanya kemungkinan ketidakpuasan pasien dengan pelayanan yang diberikan puskesmas.

\section{Metode}

Penelitian ini menggunakan rancangan penelitian kuantitatif dengan pendekatan Cross-Sectional. Populasi dalam penelitian ini diperkirakan populasi pada penelitian ini adalah 64, dengan table acuan sampel Mogran dan Krejcie dalam pengukuran indeks kepuasan masyarakat maka, jumlah sampel dalam penelitian ini adalah sebanyak 59 responden (PERMENPAN RB No. Nomor 14 Tahun 2017). Tehnik pengambilan sampel dilakukan secara accidental sampling. Penelitian dilakukan di Puskesmas Wonosari Kecamatan Wonosari pada bulan April sampai dengan Mei 2019. Instrument dalam penelitian ini adalah kuesioner dan observasi dengan skala gutman dan survei indeks kepuasan masyarakat. Analisa data dilakukan secara univariat dan bivariat dengan uji korelasi Spearman's Rho, dengan signifikansi $\mathrm{p}=0,05$. Jika nilai $\mathrm{p}<0,05$ maka $\mathrm{HO}$ ditolak dan $\mathrm{H} 1$ diterima yang 
artinya ada Hubungan Kualitas Pelayanan Rawat Inap Dengan Indeks Kepuasan Masyarakat

\section{Hasil Penelitian}

Data umum :

1. Karakteristik responden

berdasarkan umur

Tabel 5.1 Karakteristik Responden Berdasarkan Usia

\begin{tabular}{ccc}
\hline Umur & Frekuensi & Prosentase \\
\hline $17-25$ Tahun & 4 & $6,8 \%$ \\
$26-35$ Tahun & 16 & $27,1 \%$ \\
$36-45$ Tahun & 24 & $40,7 \%$ \\
$46-55$ Tahun & 9 & $15,3 \%$ \\
$>$ 55 tahun & 6 & $10,2 \%$ \\
\hline Total & $\mathbf{5 9}$ & $\mathbf{1 0 0} \%$ \\
\hline
\end{tabular}

Sumber : Angket Penelitian

Dari 5.1 diatas menunjukkan bahwa sebagian besar responden berusia $36-45$ tahun sejumlah 24 responden $(40,7 \%)$ dan diikuti berusia 26 - 35 tahun sejumlah 4 responden $(27,1 \%)$.

2. Karakteristik responden berdasarkan jenis kelamin

Tabel 5.2 Karakteristik Responden Berdasarkan Jenis Kelamin

\begin{tabular}{ccc}
\hline Jenis Kelamin & Frekuensi & Prosentase \\
\hline Perempuan & 40 & $67,8 \%$ \\
Laki - Laki & 19 & $32,2 \%$ \\
\hline Total & $\mathbf{5 9}$ & $\mathbf{1 0 0} \%$ \\
\hline
\end{tabular}

Sumber : Angket Penelitian

Dari tabel 5.2 diatas
menunjukkan bahwa sebagian besar responden berjenis kelamin perempuan sejumlah 40 responden $(67,8 \%)$ dan 19 responden $(32,2 \%)$ berjenis kelamin laki - laki.

3. Karakteristik responden berdasarkan pendidikan terakhir

Tabel 5.3 Karakteristik Responden Berdasarkan Pendidikan Terakhir

\begin{tabular}{ccc}
\hline $\begin{array}{c}\text { Pendidikan } \\
\text { Terakhir }\end{array}$ & Frekuensi Prosentase \\
\hline Tidak Sekolah & 2 & $3,4 \%$ \\
SD atau Sederajat & 19 & $32,2 \%$ \\
SMP atau Sederajat & 12 & $20,3 \%$ \\
SMA atau Sederajat & 19 & $32,2 \%$ \\
Perguruan Tinggi & 7 & $11,9 \%$ \\
\hline Total & $\mathbf{5 9}$ & $\mathbf{1 0 0} \%$ \\
\hline Sumber Angket Penelitian
\end{tabular}

Sumber : Angket Penelitian

Dari tabel 5.3 menunjukkan bahwa sebagian besar responden memiliki pendidikan terakhir SD atau Sederajat dan SMA atau sederajat masing - masing sejumlah 19 responden $(32,2 \%)$ dan tidak sekolah sejumlah 2 responden $(3,4 \%)$.

4. Karakteristik responden berdasarkan pekerjaan

Tabel 5.4 Karakteristik Responden Berdasarkan Pekerjaan

\begin{tabular}{ccc}
\hline Pekerjaan & Frekuensi & Prosentase \\
\hline Tidak Bekerja & 24 & $40,7 \%$ \\
Tani & 8 & $13,6 \%$ \\
Wiraswasta & 16 & $27,1 \%$ \\
Pegawai Negeri & & \\
atau Swasta & 11 & $18,6 \%$ \\
\hline Total & $\mathbf{5 9}$ & $\mathbf{1 0 0 \%}$ \\
\hline
\end{tabular}

Sumber : Angket Penelitian

Dari tabel 5.4 menunjukkan bahwa sebagian besar 24 responden $(40,7 \%)$ tidak bekerja dan sejumlah 8 responden $(13,6 \%)$ adalah petani

\section{Data Khusus :}

1. Karakteristik Kualitas Pelayanan Rawat Inap

Tabel 5.5 Karakteristik Kualitas Pelayanan Rawat Inap Puskesmas Wonosari

\begin{tabular}{ccc}
\hline $\begin{array}{c}\text { Kualitas } \\
\text { Pelayanan Rawat } \\
\text { Inap }\end{array}$ & \multicolumn{2}{c}{ Frekuensi Prosentase } \\
\hline Sangat Tidak Baik & 0 & $0 \%$ \\
Tidak Baik & 0 & $0 \%$ \\
Kurang Baik & 4 & $6,8 \%$ \\
Baik & 18 & $30,5 \%$ \\
Sangat Baik & 37 & $62,7 \%$ \\
\hline Total & $\mathbf{5 9}$ & $\mathbf{1 0 0} \%$ \\
\hline
\end{tabular}

Sumber : Angket Penelitian

Dari tabel 5.5 diatas menunjukkan bahwa kualitas pelayanan rawat inap sangat baik sejumlah sejumlah 37 responden $(62,7 \%)$, dan sejumlah 18 responden

$(30,5 \%)$

menginterpretasikan baik

2. Karakteristik Indeks Kepuasan

Masyarakat

Tabel $5.6 \quad$ Karakteristik

Indeks Kepuasan Masyarakat Puskesmas Wonosari

\begin{tabular}{ccc}
\hline $\begin{array}{c}\text { Indeks } \\
\text { Kepuasan } \\
\text { Masyarakat }\end{array}$ & Frekuensi & Prosentase \\
\hline Tidak Puas & 4 & $6,8 \%$ \\
Kurang Puas & 9 & $15,3 \%$ \\
Puas & 27 & $45,8 \%$ \\
Sangat Puas & 19 & $32,2 \%$ \\
\hline Total & $\mathbf{5 9}$ & $\mathbf{1 0 0} \%$ \\
Sumber : Angket Penelitian &
\end{tabular}

Dari tabel 5.6 diatas menunjukkan bahwa indeks kepuasan masyarakat menyatakan puas sejumlah 27 responden $(45,8 \%)$ dan sejumlah 19 responden 
$(32,2 \%)$ menyatakan sangat puas tentang pelayanan rawat inap

3. Hubungan Kualitas Pelayanan Rawat

Inap Dengan Indeks Kepuasan Masyarakat Puskesmas Wonosari Tabel $5.7 \quad$ Tabulasi Silang Hubungan Kualitas Pelayanan Rawat Inap Dengan Indeks Kepuasan Masyarakat Puskesmas Wonosari

\begin{tabular}{|c|c|c|c|c|c|c|c|c|c|c|c|c|c|}
\hline \multicolumn{14}{|c|}{ hdeks Kquasan Jhşarakat } \\
\hline & & \multicolumn{2}{|c|}{ Tidekpuas } & \multicolumn{2}{|c|}{ Kurang Puss } & \multicolumn{2}{|c|}{ Puas } & \multicolumn{2}{|c|}{ Sangat Plass } & \multicolumn{2}{|r|}{ Total } & \multirow{2}{*}{$\begin{array}{l}P \\
\text { value }\end{array}$} & \multirow{2}{*}{$\begin{array}{l}\text { Correlation } \\
\text { Coefficint }\end{array}$} \\
\hline & & $\mathrm{F}$ & $\%$ & $\mathrm{~F}$ & $\%$ & $\mathrm{~F}$ & $\%$ & $\mathrm{~F}$ & $\%$ & $\mathrm{~F}$ & $\%$ & & \\
\hline \multirow{6}{*}{$\begin{array}{l}\text { Kolitias } \\
\text { Pelay anan } \\
\text { Rearid } \\
\text { inap }\end{array}$} & Sangt Tidak Balk & 0 & $0,0 \%$ & 0 & $0, W_{0}$ & 0 & $0, \%$ & 0 & $0,0 \%$ & 0 & $0,0 \%$ & \multirow{5}{*}{0,002} & \multirow{5}{*}{0,714} \\
\hline & TidakBak & 0 & $0,0 \%$ & 0 & $0, N_{0}$ & 0 & $0, \%$ & 0 & $0,0 \%$ & 0 & $0, \%$ & & \\
\hline & Kurang Balk & 4 & $6.8 \%$ & 0 & $0, \%$ & 0 & $0, \%$ & 0 & $0,0 \%$ & 4 & $6,8 \%$ & & \\
\hline & Bad & e & $0,0 \%$ & 8 & $13, \%$ & 10 & $169 \%$ & 0 & $0,0 \%$ & 18 & $30.9 \%$ & & \\
\hline & Sanga Baik & 0 & Q0\% & 1 & $1,7 \%$ & 17 & $28,8 \%$ & 19 & $322 \%$ & 37 & $62 \%$ & & \\
\hline & Total & 4 & $688 \%$ & 9 & $153 \%$ & 27 & $45,8 \%$ & 19 & $32,2 \%$ & 59 & $100,0 \%$ & & \\
\hline
\end{tabular}

Sumber : Angket Penelitian

Dari hasil SPSS (Statistikal Package for the Social Sciens) uji statistik

Spearman Rank dengan derajat kemaknaan $p<0,05$. Didapatkan $\mathrm{p}$ value 0,000 yang berarti Ho ditolak dan H1 diterima maka, Ada Hubungan Kualitas Pelayanan Rawat Inap Dengan Indeks

Kepuasan Masyarakat Puskesmas Wonosari dengan tingkat Correlation Coefficient 0,714.

\section{PEMBAHASAN}

\section{Interpretasi Dan Diskusi Hasil a. Kualitas Pelayanan Rawat Inap}

Berdasarkan tabel 5.5, persepsi responden terhadap kualitas pelayanan rawat inap menginterpretasikan sangat baik sejumlah 37 responden (62,7\%) dan baik sejumlah 18 responden $(30,5 \%)$ serta terdapat interpretasi kurang baik sejumlah 4 responden $(6,8 \%)$ tentang kualitas pelayanan rawat inap.

Dari hasil penelitian ini didapatkan sebagian besar responden berusia 36 - 45 tahun sejumlah 24 responden (37\%) dan terendah adalah responden berusia $17-25$ tahun sejumlah 4 responden (6,8\%). Dapat disimpulkan bahwa sebagian besar usia responden berada dalam usia produktif, setiap klien dan keluarga menginginkan perhatian dan setiap keluhannya ingin didengar oleh tenaga kesehatan khususnya dokter dan perawat terutama sewaktu sakit.
Pada tabel 5.3 menunjukkan sebagian besar responden memiliki pendidikan terakhir SD atau Sederajat dan SMA atau sederajat sejumlah 19 responden $(32,2 \%)$ dan terendah adalah responden tidak sekolah sejumlah 2 responden $(3,4 \%)$. $\mathrm{Hal}$ ini berarti bahwa klien atau keluarga memiliki tingkat pendidikan yang cukup tinggi, maka dengan mudah dapat memberikan persepsi gambaran tentang kualitas pelayanan kesehatan.

\begin{tabular}{lcr}
\multicolumn{2}{c}{ Dengan demikian } & dapat \\
diartikan & bahwa semakin & baik \\
kualitas pelayanan melalui & lima \\
dimensi pelayanan maka akan
\end{tabular}
semakin meningkat kepuasan pasien selama berobat ke Puskesmas dan dapat meningkatkan loyalitas pasien untuk selalu berobat ke Puskesmas jika mereka sakit dan membutuhkan pelayanan kesehatan.

Dari hasil penelitian ini dapat disimpulkan bahwa secara umum kualitas pelayanan rawat inap dapat dikategorikan baik dan hal ini sejalan dengan visi dan misi tempat penelitian yang senantiasa berupaya memberikan pelayana $\mathrm{n}$ kesehatan yang optimal. Makna kualitas pelayanan rawat inap disini merupakan hal yang dirasakan oleh klien atau keluarga saat mendapatkan layanan kesehatan baik yang diberikan perawat dan dokter sehingga merasa memenuhi harapan klien dan keluarga. Sejalan dengan penelitian Ika Andriyani (2016) yang menyatakan bahwa Hal ini berarti pasien memiliki tingkat pendidikan yang cukup tinggi. Dengan pendidikan yang cukup tinggi, sudah dapat memberikan persepsi gambaran tentang kualitas pelayanan dan memberikan penilaian kepuasan terhadap pelayanan yang diterima selama menjadi pasien.

\section{b. Indeks Kepuasan Masyarakat}

$\begin{array}{ccc}\text { Dari tabel } & 5.6 & \text { diatas } \\ \text { bahwa } & \text { indeks }\end{array}$
kepuasan masyarakat tidak puas sejumlah 4 responden $(6,8 \%)$, kurang puas sejumlah 9 responden $(15,3 \%)$, dan puas sejumlah 27 responden (45,8\%). Sedangkan indeks kepuasan masyarakat sangat puas sejumlah 19 responden $(32,2 \%)$.

Survei Kepuasan Masyarakat merupakan kegiatan pengukuran 
secara komprehensif tentang tingkat kepuasan masyarakat terhadap kualitas layanan yang diberikan oleh penyelenggara pelayanan publik. sedangkan Indeks Kepuasan Masyarakat adalah hasil pengukuran dari kegiatan Survei Kepuasan Masyarakat berupa angka. Angka ditetapkan dengan skala 1 (satu) sampai dengan 4 (empat). Berdasarkan prinsip pelayanan sebagaimana telah ditetapkan dalam keputusan Menteri Pendayagunaan Aparatur Negara Nomor 14 Tahun 2017, yang kemudian dikembangkan menjadi 9 unsur yang relevan, valid dan reliabel sebagai unsur minimal yang harus ada untuk dasar pengukuran. Standart penilaian pengukuran indeks kepuasan masyarakat, yang terbagi menjadi unsur antara lain : Persyaratan, Sistem, Mekanisme, dan Prosedur, Waktu Penyelesaian Biaya/Tarif, Jenis Pelayanan, Kompetensi

Pelaksana, Perilaku Pelaksana, Penanganan Pengaduan, Saran dan Masukan serta Sarana dan prasarana Kepuasan Masyarakat yang dapat diterapkan pada Institusi pelayanan public.

Kepuasan tersebut dirasakan oleh klien atau keluarga saat menerima layanan kesehatan di puskesmas, hal ini ditunjukkan berdasarkan nilai rata - rata alat ukur indeks kepuasan masyarakat, dimana sebagian besar responden menilai rata - rata pelayanan kesehatan di rawat inap Puskesmas Wonosari adalah sebesar 3,0644 3,532 dengan nilai interval konversi 76,61 - 88,30, dan dikategorikan kedalam ketegori puas sesuai keputusan Menteri Pendayagunaan Aparatur Negara Nomor 14 Tahun 2017. Menelaah lebih dalam pada indeks kepuasan per unsur didapatkan bahwa kecepatan waktu pelayanan, kewajaran biaya atau tarif dan kesesuaian produk pelayanan antara yang tercantum dalam standar pelayanan dengan hasil yang diberikan menunjukkan nilai perunsur yang relative tinggi yaitu > 87, artinya bahwa unsur tersebut menjadi penilaian tertinggi masyarakat terhadap kepuasan masyarakat dalam mengakses layanan kesehatan di rawat jalan Puskesmas Wonosari. Evaluasi yang dilakukan secara continue terhadap kepuasan menjadikan tolak ukur dalam pemberian pelayanan kesehatan (dr. M. Hardhantyo PW, 2014).

\section{c. Hubungan Kualitas Pelayanan Rawat Inap Dengan Indeks Kepuasan Masyarakat Puskesmas Wonosari}

Hasil Uji statistik Spearman Rank dengan derajat kemaknaan $p<$ 0,05 . Didapatkan $\mathrm{p}$ value 0,000 yang berarti Ho ditolak dan H1 diterima maka, Ada Hubungan Kualitas Pelayanan Rawat Inap Dengan Indeks Kepuasan Masyarakat Puskesmas Wonosari.

Berdasarkan data penelitian menunjukkan tinggi rendahnya tingkat kepuasan pasien dipengaruhi oleh tinggi rendahnya kualitas pelayanan yang diberikan. Kualitas pelayanan sangat menentukan kepuasan masyarakat terhadap layanan yang berikan. Lima dimensi pelayanan khususnya dalam pelayanan rawat inap meliputi Reliabilitas (Reliability), Daya Tanggap (Responsiveness), Jaminan (Assurance), Empati (Empathy), dan Bukti Fisik (Tangible) merupakan hal yang tidak dapat dipisahkan dan secara signifikan dapat mempengaruhi kepuasan kepada masyarakat.

Hasil penelitian ini didukung oleh penelitian yang dilakukan oleh Erviana (2013) yang meneliti tentang pengaruh kualitas pelayanan dan kepercayaan terhadap kepuasan pasien rawat inap, hasilnya diperoleh bahwa variabel kualitas pelayanan berpengaruh positif terhadap kepuasan pasien rawat inap. Persepsi kualitas pelayanan yang baik akan sangat berpengaruh terhadap kepuasan pasien. Ini berarti semakin baik kualitas pelayanan berakibat pada semakin baiknya kepuasan pasien.

Dengan demikian dapat diartikan bahwa semakin baik kualitas pelayanan melalui lima dimensi pelayanan maka akan semakin meningkat kepuasan pasien selama berobat ke Puskesmas dan dapat meningkatkan loyalitas pasien untuk 
selalu berobat ke Puskesmas jika mereka sakit dan membutuhkan pelayanan kesehatan

\section{SIMPULAN}

Kualitas pelayanan rawat inap yang mencakup Reliabilitas, Daya Tanggap, Jaminan, Empati, dan Bukti Fisik sebagian besar dikategorikan baik.

\section{DAFTAR PUSTAKA}

Al-Qur'an dan Terjemahan, diakses pada tanggal 12 Februari 2019

Anggraeny C. 2013. Inovasi pelayanan kesehatan dalam meningkatkan kualitas pelayanan.

Bustami, 2011. Penjaminan Mutu Pelayanan Kesehatan Dan Askeptabilitasnya. Surabaya: Erlangga.

Danang, Sunyoto. 2012. Manajemen Sumber Daya Manusia. Jakarta: PT Buku Seru.

Daryanto dan Setyobudi Ismanto. 2014. Konsumen dan Pelayanan Prima. Malang: Gava Media

Departemen Kesehatan RI, 2014. Kebijakan Dasar Pusat Kesehatan Masyarakat Tahun 2014. Penerbit Depkes RI. Jakarta.

Departemen Kesehatan RI, 2014. Manajemen Puskesmas 2014. Penerbit Depkes RI. Jakarta.

DR. H. Mulyadi, Dedi SE., MM., dkk. Analisis Peran Kepemimpinan Terhadap Motivasi Kerja Pegawai Pada Departemen Fasilitas Umum dan Penataan Lingkungan Perum Peruri. Jurnal Manajemen.2013.

dr. M. Hardhantyo PW, : Al Abri et al., Patient Satisfaction Survey as a Tool Towards Quality Improvement. Oman Medical Journal (2014) Vol. 29, No. 1:3-7.Diakses pada tanggal 18 Maret 2019

Erna Fitriyanah. 2017. Perbedaan Tingkat Kepuasan Pasien BPJS dan Pasien Umum Tentang Mutu Pelayanan Keperawatan Unit Rawat Inap Kelas 3 RSUD dr. H. Soewondo. Kendal, Jurnal STIKES Telongorejo. Semarang

Heru Herwanto, 2015. Tugas Akhir Program Magister tentang Kualitas Pelayanan Kesehatan, Universitas Terbuka Jakarta.
Jacobalis, S. 2013. Manajemen Mutu Pelayanan Rumah Sakit. Jakarta: Persi.

Kemenkes RI. 2014. Permenkes RI No 75 Tahun 2014 tentang puskesmas. Jakarta: Depkes RI.

Keputusan Menteri Kesehatan RI No 828/Menkes/SK/IX/2008Tentang PetunjukTehnis Standar Pelayanan Minimal Bidang Kesehatan di Kabupaten / Kota

Kotler, P. \& Keller, K.L. 2014. Manajemen Pemasaran (Edisi 12). Jakarta: PT Indeks

Kotler, Philip. 2012. Manajemen Pemasaran. Edisi Kesebelas, Jakarta: Indeks Kelompok Gramedia.

Lestari D,DKK. 2015. Indikator user satisfaction dalam layanan $E$ learning. Jurnal keperawatan. Jurusan Pendidkan Matematika FMIPA UNY. 